\title{
A perspectiva pragmática nas pesquisas sobre prática instrumental: condições e implicações procedimentais
}

\author{
Regina Antunes Teixeira dos Santos (UFRGS, Porto Alegre) \\ jhsreg@adufrgs.ufrgs.br
}

Liane Hentschke (UFRGS, Porto Alegre)

liane.hentschke@portoweb.com.br

Resumo. Pesquisas em prática instrumental evidenciam tendências que expressam certos aspectos de racionalidade calculada da ação e apontam para uma perspectiva pragmática de engajamento pessoal frente às situações de prática. Sistematizações sobre modos intencionais de proceder na prática instrumental em conexão com níveis de especialização músico-instrumental encontram-se não somente nos resultados dessas pesquisas, mas também implícitos nos conceitos de prática. Assim, o presente artigo discute a natureza e a finalidade das condições procedimentais implícitas nos conceitos e resultados de pesquisas em prática instrumental. Implicações procedimentais apresentam-se também nas discussões referentes à quantidade e a qualidade na prática, e justificam a existência de níveis diferenciados de especialização músico-instrumental na prática. 0 presente artigo aborda ainda a relação entre procedimentos e estratégias de prática. Palavras-chave: prática instrumental em música, procedimentos em música, estratégias em música.

\section{A pragmatic perspective in instrumental practice research: conditions and procedural implications}

\begin{abstract}
Research in instrumental practice has shown some trends that express certain aspects of calculated rationality, and point out to a pragmatic regime of personal commitment during practice. The systematization of the intentional procedures of the performer in order to improve and to refine one's music expertise level is present in research as well as in the concepts of instrumental practice. Thus, the present article discusses the nature and the goals of the procedimental conditions implicit in the concepts and research results in instrumental practice. Procedimental implications are also present in the discussion of the role of quantity and quality in the practice and justify the existence of different levels of instrumental expertise in the practice. This article also raises the relationship between procedures and strategies of practice.
\end{abstract}

Keywords: instrumental practice in music, music procedures, music strategies.

\begin{abstract}
1. Introdução
A prática instrumental vem sendo mais intensamente pesquisada nos últimos 20 anos. Pesquisas têm sido delineadas sob tendências da psicologia social e cognitiva, e apontam certos aspectos da racionalidade calculada da ação, ou seja, uma racionalidade de meios para se alcançar os fins desejados, dentro de uma perspectiva pragmática (vide, por exemplo, THÉVENOT, 2001). Em outras palavras, essas pesquisas evidenciam as potencialidades do planejamento intencional de instrumentistas, frente às situações de prática, e voltam-se à sistematização de aspectos que possibilitem a melhoria e o refinamento do nível de especialização músico-instrumental.
\end{abstract}

A literatura nacional e internacional tem discutido sobre os avanços dessas pesquisas a fim de compreender e divulgar aspectos referentes aos conceitos sobre prática, aos niveis de especialização instrumental, assim como recursos estratégicos frequentemente utilizados nas situações de prática instrumental (vide, por exemplo, HALLAM, 1997a; 1997b; NIELSEN, 1997; 1999; LAGE et al., 2002; ROHWER, 2002, JØRGENSEN, 2004; WILLIAMON, 2004; SANTIAGO, 2006b). É possivel perceber que existe um consenso de que a prática instrumental acaba dependendo da natureza e do contexto da tarefa, do nível de especialização dos instrumentistas, e de suas diferenças individuais, assim como dos interesses e engajamentos ai envolvidos (SLOBODA et al., 1996; HALLAM, 1997b; DAVIDSON et al., 1998; WEISSBERG, 1999; GABRIELSSOHN, 1999; 2003; BARRY e HALLAM, 2002; KRAMPE, 2006).

Para estudantes, professores e instrumentistas profissionais, as situações de prática constituem uma 
atividade fundamental no dia-a-dia, compreendendo a utilização de uma série de procedimentos aprendidos ou criados em dependência das necessidades pessoais. Entendem-se aqui como procedimentos músicoinstrumentais os modos de proceder e agir balizados por normas e convenções, fundamentadas por uma determinada tradição cultural como aquela da denominada música clássica ocidental. Pesquisadores têm investigado as situações de prática de instrumentistas proficientes e profissionais, assim como de estudantes, iniciantes ou avançados, buscando identificar as condições procedimentais implícitas nas situações de prática. Assim, o presente artigo visa discutir a natureza e a finalidade das condições procedimentais da prática implícitas nos conceitos e resultados de pesquisas em prática instrumental. Implicações procedimentais apresentam-se também nas discussões referentes à quantidade e a qualidade na prática, e justificam a existência de níveis diferenciados de especialização músico-instrumental na prática.

\section{A natureza e finalidade das condições procedimentais implícitas nos conceitos de prática}

0 conceito de prática deliberada introduzido por ERICSSON, KRAMPE e TESCH-ROMER (1993) refere-se às atividades, especificamente delineadas, com vistas a melhorar certo nivel de performance. Tal conceito de prática instrumental sugere padrões de condutas otimizadas que privilegiam uma natureza racional e calculada das ações para gerenciar tais situações, implicando postura intencional frente às situações de prática, onde o foco de interesse é atingir o domínio das condições de performance. Assim, a atitude frente à prática é deliberada quando procura intencionalmente:

(i) Estabelecer uma tarefa bem definida que represente um desafio pessoal a ser vencido;

(ii) Manter-se o mais consciente possivel no curso da tarefa a ser vencida.

(iii) Dispor de persistência para repetir trechos e corrigir eventuais erros;

(iv) Buscar estratégias alternativas para persistir e esforçar-se no comprometimento frente às tarefas dificeis de serem realizadas.

Os procedimentos empregados nesse tipo de prática poderão conter finalidade operacional e organizacional dependentes das possibilidades pessoais do instrumentista. Para WEISSBERG (1999), o ângulo de visão sobre as possibilidades da prática deliberada tem relação com o nível de especialização e conhecimentos acumulados do instrumentista. Assim, esse autor adverte-nos que estudantes/instrumentistas em formação precisam de suporte e orientação apropriados para que as tarefas delimitadas possam ser praticadas de forma deliberada, e que tal deliberação possa contribuir ao refinamento artistico da obra estudada a longo prazo.

0 conceito de prática como auto-ensino de JØRGENSEN (2004) traz a noção de procedimentos situacionais de natureza reflexiva, com foco de interesse centrado na gestão cíclica da prática. Assim, uma disposição para a prática é a de auto-ensino quando contempla:

(i) 0 planejamento da prática em termos de estabelecer o que será feito, levando em conta os processos e crenças pessoais que precedem os esforços em uma dada tarefa. Nessa etapa, temse o planejamento dos procedimentos a serem realizados, abarcando intencionalmente aspectos situacionais, físicos, musicais e emocionais.

(ii) A execução do planejamento, através da realização dos procedimentos de prática (e de performance) escolhidos previamente, sejam esses para a capacitação física e psicológica para as situações em questão, sejam esses, procedimentos de ajuste sobre o planejamento previamente esboçado.

(iii) Observação e avaliação dos procedimentos executados através de critérios explícitos sobre as experiências de prática e/ou de performance.

0 conceito de prática como auto-ensino traz a noção procedimental com finalidade organizacional e operacional de forma equilibrada, uma vez que a relação cíclica das situações da prática pode favorecer momentos pontuais de cunho avaliativo para reestruturar o curso das decisões da prática.

Os conceitos de prática efetiva foram trazidos por HALLAM (1997a) e WILLIAMON (2004), e possuem significados específicos. Para HALLAM (1997a), prática efetiva é aquela que atinge o produto-alvo, em menor tempo possivel, sem que interfira nas metas em longo prazo. Em outras palavras, o procedimento como um todo tem a finalidade operacional de economia de tempo e de esforço. HALLAM (1997a) considera que esse conceito permite que a prática assuma muitas formas, e acaba trazendo a necessidade de desenvolvimento da metacognição para facilitar a realização das atividades, ou no caso de estudantes em formação, uma perspectiva de buscar 0 aspecto efetivo na prática, a partir da autoavaliação, reflexão e hipotetização, visando a economia de tempo e esforço, sem acarretar prejuízo na qualidade de sua execução musical.

A metacognição nas situações de prática instrumental implicaria um tipo de raciocínio voltado a elaborar perguntas do tipo: De que maneira eu faria essa passagem? Por que tal modo de realização é tão difícil para mim? Nessa maneira de fazer, o que é específico as minhas próprias possibilidades pessoais? 0 que poderia fazer para melhorar minha execução? A profundidade desses questionamentos depende tanto do nível de especialização, como da capacidade reflexiva do instrumentista. Por isso mesmo, para HALLAM (1997a), o sentido efetivo da prática dependerá do nível de habilidade instrumental atingido, das especificidades das tarefas concebidas em função do contexto, da relação entre habilidades a serem adquiridas e aquelas a serem mantidas, além das próprias diferenças individuais. 
Ao considerar que prática efetiva assuma formas diferenciadas em função dos procedimentos de natureza metacognitiva, HALLAM (1997a) adverte-nos de que há um limite deaprofundamento que um dado problema situacional poderá ser contemplado pelos estudantes/instrumentistas, tendo em vista, principalmente, formas idiossincráticas de pensamentos previamente realizados. Nesse sentido, a responsabilidade do professor de instrumento seria de incentivar processos de pensamentos de natureza reflexiva e também crítica para vencer as barreiras e dificuldades pessoais frente às obras em preparação.

Contemplar tal postura frente às situações de prática implicaria a condição procedimental de pensar sobre as especificidades (e tendências) dos próprios pensamentos, sejam esses mentais e/ou aqueles expressos através de ações. Para KUHN (1999), a metacognição está relacionada à reflexão crítica, que, por sua vez, pode também contemplar meta-afetividade, através da qual se gerencia e controla uma ação afetiva para as experiências. Nessa linha de pensamento, a prática é um processo ativo no qual (meta)cognição e (meta)afetividade estão intimamente relacionadas. Quando presentes, tais pensamentos críticoreflexivos estão voltados a identificar as maneiras de proceder em termos de procedimentos organizacionais e operacionais das situações de prática, estando intimamente voltados a vencer as barreiras e melhorar as possibilidades pessoais sejam essas de natureza física, cognitiva e emocional, por exemplo.

Para WILLIAMON (2004), o conceito de prática efetiva é utilizado em referência à excelência musical em termos de performance artística. Esse tipo de prática, realizada por instrumentistas proficientes e profissionais, dispõe de uma natureza crítico-reflexiva, contemplando a noção procedimental de organização e operacionalização de forma equilibrada, pois deve levar em conta cinco fatores inter-relacionados, a saber:

(i) Concentração: entendida como uma dilatação temporal no período da prática em termos de pensamentos musicais voltados a atingir 0 melhor resultado possível no contexto musical em questão, incluindo o esforço de escutar-se durante a prática. ${ }^{1}$

(ii) Estabelecimento de metas exeqüíveis: estímulo aos procedimentos operacionais voltados ao isolamento e refinamento de partes específicas, por exemplo. ${ }^{2}$

(iii) Constante auto-avaliação para ponderar falhas e sucessos na performance, bem como buscar potenciais retroalimentações necessárias. ${ }^{3}$

(iv) Uso de estratégias flexíveis, moldadas e redirecionadas conforme a situação em escrutínio. ${ }^{4}$

(v) Visualização de um plano global, a fim de ter idéia do formato expressivo como um todo, enquanto toma decisões sobre considerações técnicas. ${ }^{5}$
Assim, conforme exposto anteriormente, podese argumentar que embora o sentido de prática efetiva para HALLAM (1997a) e WILLIAMON (2004) tenham significados e direcionamentos distintos, as concepções implícitas nesses conceitos acabam sendo complementares. Enquanto WILLIAMON (2004) contempla bases para prática de estudantes a partir de instrumentistas proficientes e profissionais, o conceito empregado por HALLAM (1997a) abarca a necessidade de se fomentar no estudante/instrumentista, formas de pensamento sobre suas necessidades frente às situações de aprendizagem enfrentadas. Nesse sentido, o conceito de prática efetiva de HALLAM (1997a) parte da finalidade primordial de se obter um produto-alvo inicial sobre a obra em preparação, o mais rápido possível e, a partir desse produto preliminar, desenvolver formas de pensamento situacionais para vencer as próprias dificuldades em questão. Podemos perceber, assim, que o principio procedimental das interações de ensino e aprendizagem, com base numa prática efetiva no sentido de HALLAM (1997a), seria a descoberta pessoal do modo de proceder pelo aluno, a partir do suporte do professor. Por outro lado, os fatores trazidos na revisão de WILLIAMON (2004) têm o potencial de fortalecer a estrutura da prática de estudantes/instrumentistas, uma vez que fornece disciplinas procedimentais a serem contempladas em uma situação de prática. A visualização do plano global da obra em preparação traz a condição de uma concepção expressiva da obra, como referência para as decisões sobre o quê perseguir ao praticar (Vide, por exemplo, CHAFFIN et al., 2003).

Para SLOBODA et al. (1996), a natureza e o contexto das tarefas investigadas acabam implicando perspectivas diferenciadas de prática, que foi denominada de formal e informal. A prática informal corresponderia àquelas situações contidas na aprendizagem instrumental que contemplam performance de peças previamente estudadas e/ou elaboração de arranjos instrumentais (a partir de músicas tiradas de ouvido, por exemplo), ou ainda atividades de improvisação e composição. A perspectiva formal da prática encontra-se, segundo SLOBODA (2005), naquelas situações da tradição da denominada música clássica ocidental, onde se deve preparar e construir uma interpretação, de forma mais fiel possivel da partitura impressa a partir de suas próprias vivências com essa tradição (vide, por exemplo, SLOBODA, 2005; SANTIAGO, 2006a). Segundo SLOBODA et al. (1996), a prática formal de um repertório pode envolver estratégias deliberadamente concebidas, envolvendo concentração e esforço, o que as aproxima, nesse sentido, da definição de prática deliberada de ERICSSON, KRAMPE e TESCH-ROMER (1993).

Mesmo que a prática formal tenha como foco de interesse a interpretação de obras musicais com base em certa referência estilística a partir de uma partitura impressa, essa abordagem poderá restringir-se a uma execução mecânica ou ainda a uma interpretação reprodutiva. A natureza da prática dita formal 
dependerá do instrumentista. Essa poderá tanto dispor de uma racionalidade calculada, envolvendo estratégias bem definidas que serão perseguidas com esforço e concentração ( $\mathrm{e}$, nesse caso, ser deliberada, como argumenta Sloboda), ou então, por exemplo, dispor de uma postura mais intuitiva, que não necessariamente seja menos eficaz que aquela deliberadamente calculada (vide, por exemplo, RINK (2006), HOLMES (2005)). Já a natureza da prática informal tende a ser muitas vezes tácita, e mesmo reflexiva, uma vez que ela intensifica a experiência musical através de atividades que privilegiem: (i) o desenvolvimento cinestésico e aural (como tocar músicas de ouvido, por exemplo), (ii) o desenvolvimento da imaginação tímbrica, através da produção de arranjos e a atividades de composição, por exemplo; (iii) o desenvolvimento da representação estrutural e/ou simbólica, da concentração na ação, através de atividades de improvisação. Cabe salientar que a consciência expandida nas atividades de improvisação em geral é considerada um indício de criatividade (vide, por exemplo, PRESSING, 2000).

Os conceitos de prática deliberada, prática como autoensino e prática efetiva até aqui discutidos implicam condições procedimentais, contemplando naturezas

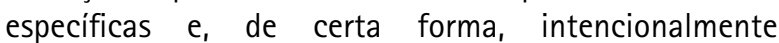
complementares. Os conceitos de prática formal e informal, embora englobem também a noção procedimental, apresentam ainda perspectivas diferenciadas (e complementares) da prática.

Os diferentes conceitos na literatura de prática instrumental apresentam, portanto, uma tendência pragmática de pensamento tendo em vista que a maioria deles busca, de alguma forma, colocar a prática como uma situação experiencial a ser enfrentada de maneira funcional, na medida em que os eventos situacionais são vivenciados intencionalmente. Nessa perspectiva pragmática, existe a crença de que os procedimentos estruturados com finalidade organizacional e/ou operacional podem ser mais eficientes, pois esses possuem a natureza intencional da ação calculada. Entretanto, não se deve negligenciar que cada instrumentista tem uma maneira particular de compreender os procedimentos encorpados em sua prática, e o tipo dessa prática depende de seu modo de ser e de compreender no mundo (vide, por exemplo, SANTOS, 2007).

Uma outra perspectiva discutida na literatura de prática instrumental refere-se à quantidade de horas acumuladas e a qualidade na prática instrumental. Argumentos sobre a quantidade de horas acumuladas na prática referem-se a condições intrínsecas e fundamentais para o instrumentista desenvolver, fortalecer e refinar as habilidades fisiológicas no instrumento. Argumentos sobre qualidade de prática refletem sobre condições procedimentais existentes na prática de instrumentistas, sejam esses estudantes ou profissionais, ponderando sobre quais condições favorecem um nível de excelência artística nas situações de prática. Assim, a seguir, serão abordadas questões procedimentais implícitas nas discussões sobre quantidade e qualidade de prática instrumental.

\section{A quantidade e qualidade na prática: questões procedimentais}

$\mathrm{Na}$ literatura, existe consenso sobre a necessidade de constância nas situações de prática para melhorar o nível de especialização instrumental. ERICSSON, KRAMPE e TESCH-ROMER (1993) demonstraram que mudanças fisiológicas em profissionais ocorrem com o acúmulo de horas de prática. Segundo esses autores, necessita-se mais de 10.000 horas de estudo de repertório e prática para um refinamento da técnica instrumental.

SLOBODA et al. (1996), corroborando com os resultados obtidos por ERICSSON, KRAMPE e TESCH-ROMER (1993), constataram através de um estudo longitudinal com 257 estudantes, de que é necessário um número consistente de horas acumuladas para que jovens instrumentistas adquiram progresso nas situações de prática: cerca de 2.500 horas acumuladas para idade de 13 anos, 6.500 horas para 17 anos e 10.000 horas para a idade de 21 anos. Segundo LAGE et al. (2002, p.18), a prática dita deliberada, consolida-se em estágio avançado de especialização instrumental, aproximadamente após 15 anos de prática.

Essas pesquisas têm demonstrado que durante as situações de prática, a aprendizagem de um instrumento musical envolve programas motores, construídos e fortalecidos à medida que uma peça musical é trabalhada durante os ensaios. 0 termo programas motores foi cunhado pelo psicólogo americano Karl Lashley (1890-1958) para referir-se a padrões de seqüências de movimentos, nos quais toda uma série de movimentos encontra-se planejada antes da sua execução (LIEPERT et al., 1998).

Programas motores subentendem habilidades humanas de natureza psico-fisiológicas, adquiridas frente a uma determinada área de conhecimento. Assim, podemospensar que na prática instrumental, a aquisição de programas motores relaciona-se com formas procedimentais de aquisição de conhecimentos técnico-instrumentais, que são adquiridos e desenvolvidos em níveis qualitativamente diferenciados. A maneira de proceder instrumentalmente pode restringir-se a um nível muito elementar (como por exemplo, controle de materiais), mas também pode atingir o controle da expressão musical perante um determinado estilo. Programas motores revelam, portanto, formas diferenciadas de conhecimento procedimental perante a prática instrumental. Cabe salientar, que conhecimento procedimental é aqui considerado como aquele adquirido e desenvolvido ao longo da prática, referente ao saber fazer algo habilmente, de maneira a incluir julgamentos normativos em relação a padrões, tradições e éticas de um certo domínio e também, conhecimento no sentido de compreender princípios, disponibilizados em situações contextualizadas (vide, por exemplo, ELLIOT, 1995). 
Nos programas motores desenvolvidos perante a prática de um instrumento musical existem procedimentos operacionais que abrangem uma gama de situações de manipulação e controle de parâmetros de altura, duração, intensidade e timbre, para atingir automaticidade e espontaneidade. Pesquisas (vide, por exemplo, DAVIDSON et al. (1996); KRAMPE e ERICSSON (1996); KRAMPE (1997, 2006),LEHMANN (1997a, 1997b); ERICSSON, 1997) têm demonstrado que ao longo da especialização músico-instrumental, programas motores interconectam-se com habilidades especificamente cognitivas a fim de que a aprendizagem do todo e dos processos de execução tornem-se automáticos. KRAMPE (1997), por exemplo, observou que pianistas experientes acumularam 60.000 horas de prática, e que esse tempo prolongado de dedicação teve profundos efeitos sobre características fisiológicas e cognitivas, que acabaram influenciando a natureza das habilidades envolvidas. Segundo KRAMPE (1997), instrumentistas com idades mais avançadas acabam compensando eventuais problemas/dificuldades técnico-instrumentais por meio de possibilidades expressivas, resultando assim em uma economia de energia na prática. Enquanto estudantes encontram-se ainda aprendendo a praticar, coordenando esforço físico e mental em relação a metas direcionadas, instrumentistas profissionais experientes buscam despender menos energia física para atingir seus objetivos em menor tempo possível.

Para JØRGENSEN e LEHMANN (1997), embora exista certo consenso na literatura de que a constância e a manutenção das situações de prática melhorem o nível de especialização, não existe ainda convergência sobre como ela funciona, quais os métodos mais eficientes e de que maneira esse benefício poderia ser usufruído igualmente por todos. A especialização músicoinstrumental engloba fatores que transcendem ao aspecto do número de horas de prática, uma vez que também constatou-se que quantidade de horas acumuladas não necessariamente implica qualidade final de performance, como observaram WILLIAMON e VALENTINE (2000). Para esses autores, o fator fundamental parece ser em como a prática é organizada e planejada (WILLIAMON e VALENTINE, 2000). Assim, esses autores enfatizam a importância dos procedimentos organizacionais frente às tarefas e atividades a serem efetuadas nas situações de prática. Em relação à prática, pesquisas com instrumentistas profissionais vêm demonstrando serem esses os princípios gerativos de ordem organizacional (vide, por exemplo: MIKLASZEWSKI (1989); HALLAM (1995; 2001); CHAFFIN et al. (2003)).

Já na prática instrumental de estudantes em contexto formal, segundo McPHERSON e McCORNICK (1999), a presença de etapa de organização e planejamento dessas situações parece ser dependente tanto de fatores motivacionais, como também de perspectiva crítica frente aos desafios a serem atingidos. Em pesquisas mais recentes, esses autores enfatizam que mesmo que a prática atue como uma parte vital no desenvolvimento da capacidade de realização instrumental, essa não deveria ser considerada isolada de variáveis motivacionais (McCORNICK e McPHERSON, 2003; McPHERSON e McCORNICK, 2006). Nessas

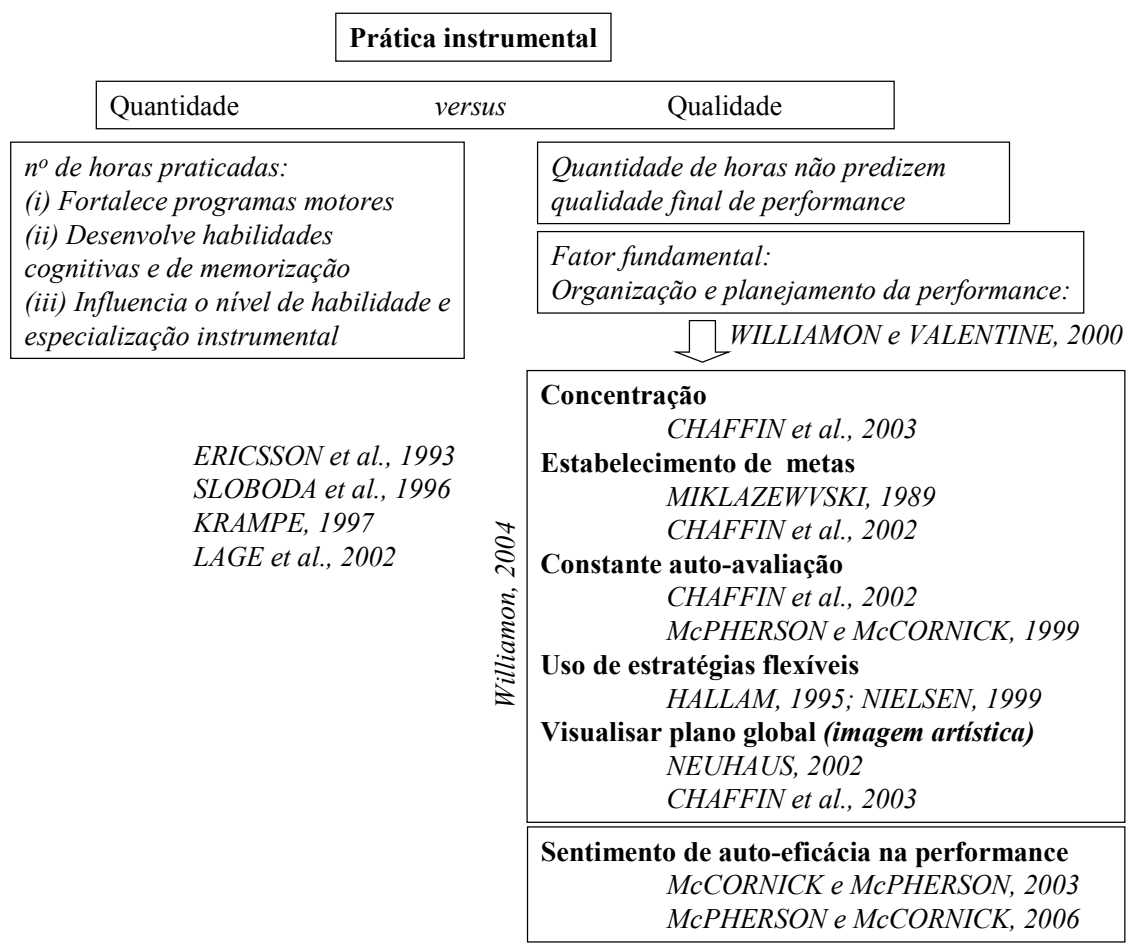

Ex.1 - Representação esquemática dos aspectos abordados em pesquisas sobre prática instrumental. 
pesquisas, os autores correlacionaram sete aspectos como possíveis variáveis do nível de desempenho de execução musical de instrumentistas frente a situações de exame departamental, a saber:

(i) número de horas praticadas;

(ii) nível de especialização;

(iii) prática formal;

(iv) prática informal;

(v) uso de estratégias cognitivas;

(vi) auto-regulação;

(vii) motivação relacionada ao sentimento de autoeficácia, ou seja, a motivação relacionada ao senso de competência e de confiança para realizar uma dada performance instrumental.

Dentre todas essas variáveis, o sentimento de autoeficácia foi a variável que mais influenciou o desempenho atingido em situações de stress, seguida de prática formal e informal (McCORMIK e McPHERSON, 2003; McPHERSON e McCORMIK, 2006).

A partir da sistematização sobre pesquisas de prática instrumental até aqui apresentadas, a relação entre quantidade e qualidade de prática pode ser sintetizada conforme o Ex.1.

De acordo com o Ex.1, encontra-se claramente estabelecido na literatura que a quantidade de horas acumuladas ao longo da prática é um fator inerente e indispensável ao nível de especialização instrumental, tendo em vista a necessidade fisiológica de desenvolvimento de programas motores. Entretanto, o aspecto da qualidade vem sendo considerado nas pesquisas, dando ênfase sobre 0 componente cognitivo, que envolve ações, em termos de planejamento, deliberação, resistência, manutenção e (auto-)avaliação. Para essas pesquisas, a quantidade de horas não implica qualidade final em performance. 0 fator fundamental da especialização através da prática combinaria, portanto, regularidade (quantidadeacumulada de horas de prática) e qualidade das tomadas de decisões, levando em conta: concentração, estabelecimento de metas, constante auto-avaliação, uso de estratégias flexíveis e visualização do plano global. Finalmente, não se pode negligenciar que pesquisas (McCORNICK e McPHERSON, 2003; MCPHERSON e McCORNICK, 2006) vêm demonstrando que o sentimento de autoeficácia na situação de performance instrumental é um fator determinante para a conexão entre performance preparada e aquela realizada.

\section{Procedimentos operacionais da prática}

Os procedimentos operacionais vêm sendo discutidos na literatura, tanto referentes à prática de profissionais como àquela de estudantes. No caso de profissionais, como apontou MIKLASZEWSKI (1995), os procedimentos acabam sendo governados por estilos pessoais de trabalho, a saber: holístico, fragmentado e misto. HARNISMACHER (1997) observou que estudantes, em sua prática, utilizam procedimentos que vão desde a realização de mecanismos instrumentais (escalas e arpejos, por exemplo) a atividades de cunho lúdico, como a improvisação e/ou o tocar de ouvido, por exemplo. 0 autor categorizou tais procedimentos em termos de quatro fatores e detalhou as caracteristicas mais relevantes observadas, que foram interpretadas e sumarizadas no Ex.2.

$\mathrm{Na}$ Ex.2, o primeiro fator (básico) refere-se a ações de reprodução de mecanismos pré-estabelecidos e sistematizados pela tradição da música clássica instrumental, visando não somente a manutenção, como o desenvolvimento de programas motores, como por

Fatores

Procedimentos

Características da prática

Básico

Tocar escalas, exercícios.

Manutenção de programas motores*

Analítico

Leitura de peças ainda desconhecidas Identificação e fragmentação das partes

Reconhecimento da peça e postura analítica frente às dificuldades encontradas

Construtivo

Estudo da peça por fragmentação das partes; Domínio crescente do todo

Planejamento e organização (das partes) para a performance

Criativo

Execução de peças conhecidas Improvisação

Manutenção do repertório e atividades lúdicas

\footnotetext{
0 autor refere-se à dimensão de "aquecimento e de exercícios de técnica instrumental (p. 85)." No presente texto, o termo "programas motores" foi selecionado para descrição dessa característica de prática, em nivel de coordenação motora, uma vez que se trata de procedimentos elementares da prática instrumental.
}

Ex.2 - Tabela de fatores, procedimentos e características da prática instrumental de jovens instrumentistas, sumarizadas a partir de HARNISMACHER (1997). 
exemplo, o exercício de realização de escalas/arpejos e/ou de aquecimento. 0 fator analítico compreende ações que requerem algum tipo de ponderação e discernimento entre as diversas partes de um todo que está sendo praticado. Esse fator pode envolver perspectivas muito diferenciadas sobre a natureza dos problemas enfrentados, em termos de ações motoras e técnicas, de ações de decodificação e de compreensão, de elementos característicos de estilo (articulações, textura, ornamentação, por exemplo) a fim de adquirir familiaridade com uma determinada tradição estilística. Embora o fator construtivo contenha alguma dimensão analítica, a prática sob essa condição enfatiza as etapas crescentes de monitoramento e de auto-avaliação visando à construção e concepção do todo. Finalmente, o quarto fator (criativo) compreende os procedimentos e realizações lúdicas e imaginativas presentes nas atividades de improvisação e de manutenção de repertório. Para o autor, esse quarto fator aproxima-se a uma concepção comumente presente em crianças e adolescentes, onde música possa vir a ser considerada como uma recompensa após o término de outras atividades diárias (HARNISCHMACHER, 1997, p. 80).

A qualidade dos produtos na prática pode ser ainda perseguida através de procedimentos de auto-avaliação. DANIEL (2001), em situação semi-experimental, investigou a auto-avaliação da performance de instrumentistas universitários e desenvolveu critérios de avaliação. ${ }^{6} 0$ autor verificou que tal procedimento apresenta-se como ferramenta altamente valiosa para as instituições de ensino superior, pois fornece uma excelente base para as discussões entre professores e estudantes sobre as performances, o que pode favorecer a autonomia pessoal. 0 desenvolvimento da capacidade de observação e de auto-avaliação das situações de prática é considerado por HALLAM (2001) como um fator de metacognição. HALLAM (2001), ao investigar a prática de estudo de 21 músicos profissionais e 15 estudantes, observou que os profissionais demonstravam um fator intenso de metacognição nas situações de prática. Esses se mostravam conscientes de seus pontos fortes e fracos, além da percepção da natureza e das exigências de diferentes tarefas, bem como de potenciais resoluções de problemas.

Embora possamos observar na literatura a existência desses procedimentos com finalidade operacional e organizacional acima discutidos, não se pode perder de vista a perspectiva individual e idiossincrática presente na prática de cada instrumentista e que será objeto de reflexão, a seguir.

\section{A perspectiva pessoal e idiossincrática na elaboração das estratégias de prática e de execução musical}

A prática instrumental formal envolve muitos procedimentos convencionais sistematizados pela tradição de ensino e aprendizagem instrumental. Em geral, esses procedimentos aprendidos têm finalidade de desenvolver e manter programas motores, leitura musical, consciência cinestésica e aural, entre outros aspectos. Para ler e avançar qualitativamente uma obra em preparação é preciso ter um repertório pessoal de procedimentos aprendidos e/ou criados, ou seja, é preciso criar uma coleção de estratégias pessoais.

Para JØRGENSEN (2004), estratégias de prática podem ser definidas como pensamentos e modos de agir que músicos utilizam em situações de prática com intenção de influenciar o estado afetivo ou incorporar novos conhecimentos musicais. Para esse autor existem três tipos de estratégias: executivas, avaliativas e metaestratégias. Estratégias executivas estão relacionadas com os modos de agir e de pensar na prática e referem-se a formas pessoais de realizar: 0 ensaio mental e no instrumento, o estudo das partes e do todo, o ensaio do andamento da peça, a distribuição do tempo da prática, a preparação da performance pública. Estratégias avaliativas estão voltadas ao diagnóstico explícito das facilidades e dificuldades pessoais na preparação de uma obra musical, e compreendem: recorrer a modelos visuais e aurais (observar-se/ escutar-se por meio de registro em áudio e/ou vídeo; observar/escutar interpretações de profissionais, por exemplo), detectar e corrigir os próprios erros, ${ }^{7}$ guiarse (em voz alta ou tacitamente) em como proceder. Finalmente, o terceiro tipo, metaestratégia, refere-se à conscientização sobre o repertório de estratégias pessoais, e intencionalmente buscar conhecer estratégias de terceiros para enriquecer seu próprio leque de opções pessoais. Assim, JØRGENSEN (2004) valoriza o aspecto idiossincrático intrínseco na escolha de estratégias.

Todas as estratégias que usamos, sejam essas aprendidas e/ou criadas, pertencem aos nossos regimes pragmáticos de familiaridade. Segundo THÉVENOT (2001), o sentido de regime pragmático de familiaridade captura a noção de privacidade, de individualidade e de autonomia, que compartilha com o meio o uso das coisas, não sob forma de algo "pronto para usar", mas como algo especialmente talhado para uso pessoal.

Os procedimentos da prática, sejam esses de finalidade organizacional e/ou operacional, são possiveis de serem atingidos graças a estratégias. Essas são formas idiossincráticas de pensamentos e de conhecimentos, tácitos e/ou explícitos, empregados para compreender e avançar as situações de prática. Procedimentos são passiveis de serem transmitidos, mas a maneira de como empregá-los dependerá da natureza daquele que está utilizando. Assim, procedimentos podem vir a ser conhecidos por estudantes/instrumentistas, mas 0 desafio maior não seria de ampliar seus conhecimentos sobre procedimentos organizacionais e operacionais, mas de buscar adaptá-los em consonância com as especificidades da prática instrumental de cada um, de forma estratégica. 


\section{Considerações Finais}

Através desse artigo, procuramos demonstrar a tendência pragmática, implícita nos conceitos de prática instrumental, que pode ser vivenciada intencionalmente através de procedimentos estratégicos com finalidade organizacional e/ou operacional. As perspectivas de planejamento intencional e de ação calculada aparecem, em maior ou menor ênfase, em todos os conceitos de prática. Essa racionalidade calculada pode expressar-se de forma mais intensa na prática dita deliberada, mas também acaba sendo contemplada na prática considerada como auto-ensino e naquelas denominada efetiva (tanto no sentido de HALLAM (1997a) como naquele de WILLIAMON (2004)).

Nos conceitos de prática formal e informal, a ênfase parece encontrar-se primeiramente nas especificidades das atividades da prática: aquela do tipo formal refere-se à prática de um repertório dentro de uma determinada tradição cultural, como aquela da música clássica ocidental, podendo ser deliberada ou não; prática informal refere-se a atividades que contemplam formas de realização com finalidade de entretenimento e que incrementam as experiências no instrumento, como a improvisação ou a composição, por exemplo.

0 principio de gerenciamento cíclico contido no conceito de prática como auto-ensino de JØRGENSEN (2004), aponta a necessidade de um nível de engajamento que contemple pensamentos e ações convergentes, ao mesmo tempo em que necessita de pensamentos de natureza reflexiva para identificar relações divergentes que precisem ser solucionadas. 0 princípio de efetividade da prática, para HALLAM (1997a), persegue a economia de tempo gasto nas situações de aprendizagem, aliado à eficiência na detecção metacognitiva das tendências de prática. No sentido atribuido por WILLIAMON (2004), prática efetiva dispõe de uma natureza crítico-reflexiva, e exige um tipo de racionalidade sustentada e balizada por convenções estilísticas da denominada música clássica ocidental.

A discussão relativa à prática instrumental aponta que os procedimentos implícitos nas pesquisas e conceitos de prática têm natureza e finalidade distintas. Quanto à natureza, os procedimentos podem ser tácitos, racionais e/ou reflexivos. 0 procedimento tácito é inerente ao instrumentista, que sabe realizar, mas não necessariamente consegue verbalizar suas ações. Por essa razão, o caráter da prática instrumental é fortemente marcado pela dimensão de tradição aural, visual e cinestésica, onde o procedimento é aprendido pela reprodução de modos de realização instrumental. Tais procedimentos podem ser mais produtivos, quando estimulados por uma atividade reflexiva sobre aquilo que está sendo aprendido e sistematizado. Além disso, reflexões sobre possibilidades distintas de realizações qualitativamente diferenciadas podem propiciar o desenvolvimento de estratégias pessoais, a serem utilizadas em contextos musicais recorrentes. Nessa mesma direção, a literatura tem nos demonstrado a necessidade de ir além da postura tácita, apontando o fato de que o instrumentista necessita acrescentar em sua prática também a ação racionalmente calculada, que busca encontrar os meios mais eficientes (e econômicos) para atingir os fins pretendidos.

Quanto à finalidade, os procedimentos da prática podem assumir uma dinâmica organizacional e/ou operacional. Os procedimentos organizacionais buscam estruturar as situações, de forma explícita ou tácita, enquanto os procedimentos operacionais delimitam o modo e a forma pela qual cada etapa será vencida. Para um estudante, os procedimentos organizacionais podem estruturar a prática em uma microescala (como no estudo diário de um instrumento), em uma mesoescala (balizado pela aula semanal de instrumento, por exemplo) ou em uma macroescala temporal (exames departamentais ou recitais, por exemplo). Da mesma forma, procedimentos operacionais podem abranger situações centradas na prática reprodutiva com vistas a vencer determinada passagem instrumental através da automatização de programas motores ou ainda aquelas de cunho analítico e/ou criativo, por exemplo. A operacionalidade em termos procedimentais acaba sendo bastante evidente nos diferentes niveis de especialização instrumental. Enquanto o iniciante, por exemplo, tende a preocupar-se em vencer a peça como um todo, perseguindo acuidade em termos de execução, um profissional, por outro lado, busca os melhores meios de atingir, de forma controlada, uma produção em termos artísticos.

Os procedimentos na prática, sejam eles organizacionais ou operacionais, são possíveis graças às estratégias pessoais elaboradas como formas idiossincráticas de pensamentos e de conhecimentos musicais, empregados para compreender e avançar as situações de prática. A estratégia pode ser considerada como o processo pessoal de organização e operacionalização dos procedimentos aprendidos e criados, pois ela é o recurso do pensamento humano que possibilita diferenças pessoais em termos qualitativos da prática. 


\section{Agradecimentos}

R.A.T. dos Santos agradece ao CNPq pela bolsa concedida.

\section{Referências}

BARRY, N.H.; HALLAM, S. Practice. In: PARNCUT, R.; McPHERSON, G.E (Eds.). The science and psychology of music performance. Oxford: University Press, p. 151-165, 2002.

CHAFFIN, R.; IMREH, G.; CRAWFORD, M. Practicing perfection: Memory and piano performance. Mahwah: Erlbaum, 2002.

CHAFFIN, R.; IMREH, G.; LEMIEUX, A.F.; CHEN, C. "Seeing the big picture": Piano practice as expert problem solving. Music Perception, v. 20, pp. 465-490, 2003.

DANIEL, R. Self-assessment in performance. British Journal of Music Education, v. 18, p. 215-226, 2001.

DAVIDSON, J.W., HOWE, M.J.A, SLOBODA, J.A. Environmental factors in the development of musical performance skill over the life span. In: The social psychology of music. HARGREAVESS, D.J.; NORTH, A.C. (Eds.). Oxford: Oxford University Press, p. 188-206, 1998.

DAVIDSON, J.W., SLOBODA, J.A., HOWE, M.J.A. The role of practice and teachers in the success and failure of instrumental learners. Bulleting of the Council for Research in Music Education, v. 127, p. 40-44, 1996.

ELLIOT, D.J. Music matters. A new philosophy of music education. New York: Oxford University Press, 1995.

ERICSSON, K.A. Deliberate practice and the acquisition of expert performance: An overview. Does practice make perfect? JØRGENSEN, H.; LEHMANN, A.C. (Eds). Oslo: Norges musikkhøgskole, pp. 9- 52, 1997.

ERICSSON, K.A.. KRAMPE, R.T., TESCH-ROMER, C. The role of deliberate practice in the acquisition of expert performance. Psychology Review, v. 100, n. 3, pp. 363-406, 1993.

GABRIELSSON, A. The perfomance of music. In: DEUTSCH, D. (Ed.) The Psychology of Music. 2 ed. San Diego: Academic Press, p. 501-602, 1999.

Music performance research at the Millenium. Psychology of Music, v. 31, p. 221-272, 2003.

HACKER, D.J. Definitions and empirical foundations. IN: HACKER D.J.; DUNLOSKY, GRAESSER, A.C. (Eds.) Metacognition in Educational Theory and Practice. London: Lawrence Erlbaum Associates, 1998, pp. 1-23.

HALLAM, S. Professional musicians' approaches to the learning and intrepretation of music. Psychology of Music, v. 21, n. 2, pp. 111-128, 1995.

Approaches to instrumental music practice of experts and novices: Implications for education. In: Does practice make perfect? JØRGENSEN, Harald; LEHMANN, Andreas C. (Eds). Oslo: Norges musikkhøgskole, pp. 89- 107, 1997 a.

What do you know about practising? Toward a model synthesising the research literature,. In: Does practice make perfect? JøRGENSEN, Harald; LEHMANN, Andreas C. (Eds). Oslo: Norges musikkhøgskole, pp. 179-231, $1997 \mathrm{~b}$.

The development of metacognition in musicians: Implications for education. British Journal of Music Education, v. 18, pp. 27-39, 2001.

HARNISCHMACHER, C. The effects of individual differences in motivation, volition, and maturational processes on practice behavior of young instrumentalists. In: Does practice make perfect? JØRGENSEN, H.; LEHMANN, A.C. (Eds). Oslo: Norges musikkhøgskole, pp. 71- 88, 1997.

HOLMES, P. Imagination in practice: a study of the integrated roles of interpretation, imagery and technique in the learning and memorization processes of two experienced solo performers. British Journal of Music Education, v. 22, pp. 217-235, 2005.

JØRGENSEN, H. Strategies for individual practice. In: Musical Excellence. Strategies and techniques to enhance performance. WILLIAMON, A. (Ed). Oxford: University Press, pp. 85-103, 2004.

JØRGENSEN, H.; LEHMANN, A.C. Does practice make perfect? Oslo: Norges musikkhøgskole, 1997.

KRAMPE, R.T. Age-related changes in practice activities and their relation to musical performance skills. In: Does practice make perfect? JØRGENSEN, H.; LEHMANN, A.C. (Eds). Oslo: Norges musikkhøgskole, pp. 165- 178, 1997.

KRAMPE, R.T. Musical expertise from a lifespan perspective. In: Musical development from a lifespan perspective. GEMBRIS, H. (Ed). Frankfurt am Main: Europäischer Verlag des Wissenschaften, pp. 91-105, 2006.

KRAMPE, R.T.; ERICSSON, K.A. Maintaining excellences. Cognitive-motor performance in pianists differing in age and skill level. Journal of Experimental Psychology: General, v. 125, pp. 331-359, 1996.

KUHN, D. A developmental model of critical thinking, Educational Researcher,v.28, n. 2, pp. 16-26, 1999.

LAGE, G.M.; BORÉM, F.; BENDA, R.N.; MORES, L.C. Aprendizagem motora na performance musical: reflexões sobre conceitos e aplicabilidade. Per Musi, v.5-6, pp.14-26, 2002.

LEHMANN, A.C. The acquisition of expertise in music: Efficiency of deliberate practice as a moderating variable in accounting forsub-expert performance. In: Perception and cognition of music. DELIĖGE, I.; SLOBODA J.A. (Eds). East Sussex: Psychology Press, pp. 161-187, 1997a. 
LEHMANN, A.C. Acquired metal representations in music performance: Anecdotal and preliminary empirical evidence. In: Does practice make perfect? JØRGENSEN, H.; LEHMANN, A.C. (Eds). Oslo: Norges musikkhøgskole, pp. 141-163, $1997 b$.

LIEPERT, J.; CLASSEN, J.; COHEN, L.G.; HALLET, M. Task-dependent changes of intracortical inhibition. Experimental Brain Research, v. 118, n. 3, pp. 421-426, 1998.

McCORNICK, J.; McPHERSON, G.E. The role of self-efficiancy in a musical performance examination: an exploratory structural equation. Psychology of Music, v. 31, n. 1, pp. 37-51, 2003.

McPHERSON, G.E.; McCORNICK, J. Motivational and self-regulated learning components of musical practice. Bulletin of the Council for Research in Music Education, v. 141, pp. 98-102, 1999.

Self-efficacy and performing music. Psychology of Music, v. 3, n. 3, pp. 321-336, 2006.

MIKLASZEWSKI, K. A case study of a pianist preparing a musical performance. Psychology of music, v. 17, pp. 95-109, 1989.

Individual differences in preparing a musical composition for public performance. In: Psychology of Music Today. MIKLASZEWSKI, K., BIATKOWSKI, A. (Eds.). Warsaw: Fryderyk Chopin Academy of Music, 1995.

NEUHAUS, H. The art of piano playing. Amersham: Halstan \& Co., 2002.

NIELSEN, S. G. Self-regulation of learning strategies during practice: A case study of a church organ student preparing a musical work for performance. In: Does practice make perfect? JØRGENSEN, H.; LEHMANN, A.C. (Eds). Oslo: Norges musikkhøgskole, 1997, pp. 109- 122.

Learning strategies in instrumental music practice, British Journal of Music Education, v. 16, p. 275-291, 1999.

PRESSING, J. Improvisation methods and models. In: Generative processes in music. SLOBODA, J.A. (Ed.). Oxford: Oxford University Press, 2000.

RINK, J. Análisis y (¿o?) interpretación. In: La interpretación musical. RINK, J. (Ed). Madrid: Alianza Música. Tradução Barbara Zitman, 2006, pp. 55-80.

ROHWER, D. Understanding practice: An investigation and applications. , v. 40, n. 1, p. 15-25, 2002.

SANTIAGO, D. Construção da performance musical: uma investigação necessária. Performance Online, v. 2, p. 1-14, 2006a.

SANTIAGO, P.F. A integração da prática deliberada e da prática informal no aprendizado da música instrumental. Per Musi, v. 13, pp. 52-62, $2006 \mathrm{~b}$.

SANTOS, R.A.T. dos. Mobilização de conhecimentos musicais na preparação do repertório pianístico ao longo da formação acadêmica: três estudos de caso. Porto Alegre: UFRGS, 2007 (Tese, Doutorado em Música).

SLOBODA, J.A. Exploring the music mind. Oxford: Oxford University Press, 2005.

SLOBODA, J.A.; DAVIDSON, J.W.; HOWE, M.J.A.; MOORE, D.C. The role of practice in the development of performing musicians. British Journal of Psychology, v. 87, p. 287-309, 1996.

THÉVENOT, L. Pragmatic regimes governing the engagement with the world. IN: SCHATKI, T.R.; CETINA, K. K.; SAVIGNY, E. von (Eds). The practice turn in contemporary theory. London: Routledge, 2001, pp. 56-73.

WEISBERG, R.W. Creativity and Knowledge: A Challenge to Theories. IN: STENBERG, R.J. (Ed.). Handbook of creativity. pp. 226-250, 1999.

WILLIAMON, A. Musical Excellence. Strategies and techniques to enhance performance. Oxford: University Press, 2004.

WILLIAMON, A.; VALENTINE, E. Quantity and quality of musical practice as predictors of perfomance quality. British Journal of Psychology, v. 91, p. 353-376, 2000.

Regina Antunes Teixeira dos Santos graduou-se em Bacharelado em Piano, na UFRGS, tendo, posteriormente, realizado cursos de especialização junto a Université Toulouse Le Mirail (Toulouse, França) e Universidade Ueno Gakkuen (Tóquio, Japão). Em 2007 concluiu doutorado sob orientação da Profa. Dra. Liane Hentschke junto ao Programa de Pós-Graduação em Música da UFRGS. Em pesquisa, sua área de interesse concentra-se na interconexão entre prática instrumental e conhecimento musical.

Liane Hentschke é Doutora em Educação Musical pela University of London, Inglaterra. Professora Titular do Departamento de Música da Universidade Federal do Rio Grande do Sul - UFRGS e Presidente da International Society for Music Education-ISME. Pesquisadora Nivel 1 do CNPq, e está desenvolvendo um projeto de pesquisa multinacional intitulado, "Os Significados da Música para Crianças e Adolescentes em Atividades Musicais Escolares e Não-Escolares", com sede nos Estados Unidos. Possui publicações de artigos científicos e capítulos de livros no exterior e no Brasil. É autora de oito livros publicados no Brasil sobre educação musical, quatro dos quais publicados pela Editora Moderna de São Paulo. No âmbito internacional têm sido convidada a proferir palestras e cursos na Inglaterra, Holanda, Estados Unidos, Espanha, Hong Kong, Argentina, Chile e Venezuela. 


\section{Notas}

1 A concentração na prática foi discutida, por exemplo, na pesquisa de CHAFFIN et al. (2003), onde a pianista investigada, apesar de praticar intensamente a peça em estudo, consumia três quartos desse tempo, refletindo sobre situações de performance.

20 estabelecimento de metas exeqüiveis foi encontrado na prática de profissionais (vide, por exemplo, MIKLAZEWSKI, 1989; CHAFFIN et al., 2002).

3 A auto-avaliação sobre os processos de prática foram encontrados tanto na prática de profissionais (CHAFFIN et al., 2002), como na de estudantes com perspectiva crítica para as situações de performance (McPHERSON e McCORNICK, 1999).

4 HALLAM (1995), entrevistando profissionais, identificou um amplo uso de estratégias flexiveis que abordavam aspectos como manutenção de habilidades, preparação para a performance e organização e gerenciamento das exigências físicas e emocionais. CHAFFIN et al. (2002) descreveram estratégias usadas por profissionais que iam desde técnicas de memorização até escolha de partes especificas a serem trabalhadas.

5 A visualização do plano global corresponde àquilo que NEUHAUS (2002) denominou de "imagem artistica" da peça.

6 Entre os critérios utilizados, pode-se citar: postura pessoal (entrada e saída do palco, formas de agradecimento, presença física, maneirismos, etc); aspectos musicais (escolha do repertório, precisão, coerência estilística); impressão geral (resposta pessoal e do público); reflexões sobre a performance registrada em áudio/vídeo em comparação com aquela percebida; reflexões sobre o progresso (conquistas e desenvolvimento desde a performance anterior); direcionamento (planos de estudo para melhorar a prática e a performance) (DANIEL, 2001, p. 219).

7 Segundo JØRGENSEN (2004), o violoncelista alemão Gerhard Mantel, relata que procura estar atento a diferentes aspectos da peça enquanto a pratica (ou seja, ir mudando o foco de atenção durante as situações de prática). Para esse intérprete, essa estratégia ajuda a se concentrar e a detectar erros (p. 96). 